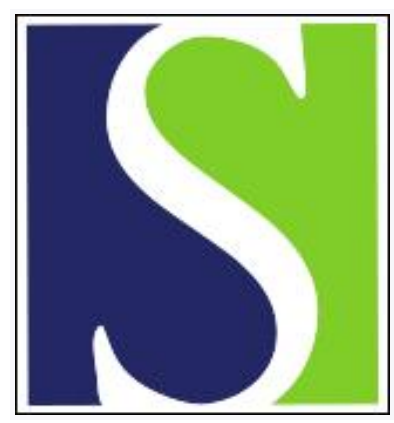

Scand J Work Environ Health 2017;43(4):385-390

https://doi.org/10.5271/sjweh.3631

Published online: 17 Mar 2017, Issue date: 01 Jul 2017

The association between blood lead levels and cardiovascular diseases among lead-exposed male workers

by Min Y-S, Ahn Y-S

The contribution of lead exposure to cardiovascular disease is not yet fully understood. This study found an association between blood lead levels and increased hospital admission of ischemic heart diseases and cerebrovascular diseases. Greater efforts are needed to reduce lead exposure for the prevention of cardiovascular diseases.

Affiliation: Department of Occupational and Environmental Medicine, Dongguk University Ilsan Hospital, Goyang-si, Gyeonggi-do, 410-773, South Korea. ysahn@dongguk.ac.kr

Key terms: acute myocardial infarction; angina pectoris; association; blood lead level; cardiovascular disease; cerebral hemorrhage; cerebral infarction; cerebrovascular disease; cohort study; CVD; IHD; ischemic heart disease; lead; nationwide cohort study; occupational exposure; worker

This article in PubMed: www.ncbi.nlm.nih.gov/pubmed/28306758

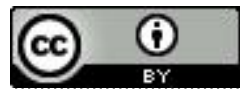




\title{
The association between blood lead levels and cardiovascular diseases among lead-exposed male workers
}

\author{
by Young-Sun Min, MD, PhD, ${ }^{1}$ Yeon-Soon Ahn, MD, PhD ${ }^{2}$
}

\begin{abstract}
Min Y-S, Ahn Y-S. The association between blood lead levels and cardiovascular diseases among lead-exposed male workers. Scand J Work Environ Health. 2017;43(4):385-390. doi:10.5271/sjweh.3631

Objective We prospectively evaluated the association between blood lead levels (BLL) and increases in hospital admissions for treatment of cardiovascular diseases among lead-exposed workers in Korea.

Methods The study cohort was derived from Korea Occupational Safety and Health Agency data, which included lead-exposed male workers who underwent lead-associated medical check-ups at least once between 2000 and 2004. The adjusted hospital admission hazard ratio (AHR) of cardiovascular diseases for each BLL grade $(10-20$ and $\geq 20 \mu \mathrm{g} / \mathrm{dL})$ was compared with that of the reference grade $(<10 \mu \mathrm{g} / \mathrm{dL})$ using Cox's proportional hazard models. The adjusted variables included age and exposure to other metals.
\end{abstract}

Results AHR of ischemic heart disease [IHD; AHR 1.78, 95\% confidence interval (95\% CI) 1.17-2.72], angina pectoris (AHR 1.93, 95\% CI 1.13-3.29) and cerebral infarction (AHR 2.24, 95\% CI 1.14-4.39) were significantly higher among workers with a BLL $\geq 20 \mu \mathrm{g} / \mathrm{dL}$ than those with a BLL $\leq 10 \mu \mathrm{g} / \mathrm{dL}$. The AHR $(1.52,95 \%$ CI 1.00-2.31) for cerebrovascular disease was significantly higher among workers with a BLL 10-20 $\mu \mathrm{g} / \mathrm{dL}$ than those with a BLL $\leq 10 \mu \mathrm{g} / \mathrm{dL}$. IHD, cerebrovascular disease, angina pectoris and cerebral infarction all showed a positive linear relationship with BLL.

Conclusions Although we were unable to control for other major risk factors such as smoking, socioeconomic status, and antihypertensive medication, we found an association between BLL and increased hospital admission for IHD, cerebrovascular disease, angina pectoris and cerebral infarction treatment. The BLL standard should be lowered to prevent the cardiovascular effects of lead exposure.

Key terms acute myocardial infarction; angina pectoris; cerebral hemorrhage; cerebral infarction; cerebrovascular disease; cohort study; CVD; IHD; ischemic heart disease; nationwide cohort study; occupational exposure.

Cardiovascular diseases are the leading cause of death worldwide and are recognized as a major public health concern. Although the major risk factors for cardiovascular diseases are hypertension, diabetes, physical inactivity, and smoking, the association between lead exposure and cardiovascular disease has attracted much attention in the field of environmental medicine (1). Lead is the most widely used nonferrous metal; almost $70 \%$ of this metal is employed to make automobile batteries. Lead is present in paint, pipes, and cables, and thus the chances of human exposure are high. The half-life of lead in blood is approximately one month (2), and the blood lead level (BLL) is regarded as the best indicator of recent lead absorption. In workers chronically exposed to lead, its half-life in bone is estimated to be 5-10 years (3).
Lead was recognized as one of the occupational risk factors of hypertension, and hypertension is risk factor for coronary heart disease, ischemic stroke, and hemorrhagic stroke (3). Moreover, in terms of the development of atherosclerosis, cumulative lead exposure triggers damage caused by oxidative stress, affecting endothelial function (4). Thus, lead exposure may be associated with an increased risk of cardiovascular diseases. Data from the National Health and Nutrition Examination Survey (NHANES) revealed a statistically significant increase in cardiovascular mortality as the BLL increased in the general population (5). A workplace study found that lead-exposed workers are at increased risk of cardiovascular incidents (6). However, previous epidemiological studies had some limitations such as intermediate out-

1 Department of Occupational and Environmental Medicine, Dongguk University Gyeongju Hospital, Gyeongju-si, South Korea.

2 Department of Occupational and Environmental Medicine, Dongguk University Ilsan Hospital, Goyang-si, South Korea.

Correspondence to: Yeon-Soon Ahn, Department of Occupational and Environmental Medicine, Dongguk University Ilsan Hospital, Goyangsi, Gyeonggi-do, 410-773, South Korea. [E-mail: ysahn@dongguk.ac.kr]. 
comes (not clinically diagnosed diseases), small sample sizes, inadequate numbers of subjects with high BLL, and a cross-sectional design. Also, a systematic review concluded that there was insufficient evidence to infer a causal relationship between lead exposure and clinical cardiovascular diseases (7).

Therefore, large-scale prospective cohort studies featuring clinical diagnoses are needed to assess the cardiovascular consequences of lead exposure. We prospectively evaluated the association between BLL and an increase in hospital admissions for treatment of cardiovascular diseases among lead-exposed workers in Korea.

\section{Methods}

\section{Study population}

Occupational hazard-related medical check-ups (evaluating 178 occupational hazards including lead) have been performed annually for Korean workers since 1972. All data have been electronically stored since 2000 by the Korea Occupational Safety and Health Agency (KOSHA). The periodic hazard-related medical checkups for lead exposure consists of an interview to collect personal information, clinical laboratory testing including BLL measurements, and health evaluation by a physician. Each worker's personal information includes his resident registration number (RRN, a 13-digit unique number), employment history in current workplace, sex, birth date, the date of commencing work in the lead-associated work position, and any other record of exposure to heavy-metals. The study cohort was derived from KOSHA data on lead-exposed male workers ( $\mathrm{N}=54$ 788) who underwent lead-associated medical check-ups at least once between 1 January 2000 and 31 December 2004.

\section{Morbidity}

In terms of morbidity, national health insurance claim data (NHICD) was used to explore the history of hospital admissions for treatment of cardiovascular disease from 2000-2005. The NHICD includes the personal RRN, the admission and discharge date, and cardiovascular disease diagnoses using the ICD-10 classification. The RRN of our cohort were matched with the RRN of the NHICD to confirm individual hospital admissions for treatment of cardiovascular diseases. Almost all hospitalized cases are registered in the NHICD database, because the Korean National Health Insurance Service has covered all Korean residents since 1989. We focused on "diseases of the circulatory system" (I00-I99); "acute rheumatic fever (I00-I02) and chronic rheumatic heart diseases" (I05-I09), "hypertensive diseases" (I10-I15), "ischemic heart dis- eases" (I20-I25), "pulmonary heart disease and diseases of pulmonary circulation" (I26-I28), "other forms of heart disease" (I30-I52), "cerebrovascular diseases" (I60-I69), "diseases of arteries, arterioles and capillaries" (I70-I79), "diseases of veins, lymphatic vessels and lymph nodes, NEC" (I80-I89), and "other and unspecified disorders of the circulatory system" (I95-I99). Acute myocardial infarction was defined as categories I21, I22, I23 and I24. Cerebral hemorrhage was defined as categories I60, I61, and I62. Cerebral infarction was defined as categories I63 and I64.

Multiple admissions of the same patient for the same category were considered a single admission. In other words, person-years were calculated for in-patients up to the first admission after cohort entry. Multiple admissions of the same patient for different categories were regarded as separate admissions. Those admitted to the hospital for cardiovascular disease treatment before cohort entry ( 818 workers) were excluded. Ultimately, 53970 participants were eligible for analysis. Personyear calculations for each worker commenced on the date of the first lead-related medical check-ups and ended on December 31, 2005, the date of the first hospitalization after the cardiovascular disease diagnosis, or the date of death, whichever came first. All participants provided written informed consent for their participation in the current cohort. The Institutional Review Board of Dongguk University Gyeongju Hospital reviewed and approved all protocols.

\section{Exposure assessment}

Individual BLL monitoring featured lead-related medical check-ups performed from 1 January 2000 to 31 December 2004. BLL were analyzed from 2000-2004 at $>100$ KOSHA-approved analytical institutions. The majority of the analytical institutions used graphite furnace atomic absorption spectrophotometry (GF-AAS), whereas a few institutions used inductively coupled plasma mass spectrometry (ICP-MS). All BLL measurement laboratories underwent semi-annual KOSHA-mandated quality control testing using a reference sample (8). All participants underwent $\geq 1$ BLL measurement during 2000-2004; the mean number of samples per worker was 2.7 , and we employed the median BLL for each individual in the analysis. According to the BLL values proposed by Schwartz and $\mathrm{Hu}(9)$, BLL were divided into three grades: $<10,10-20$, and $\geq 20 \mu \mathrm{g} / \mathrm{dL}$. Exposure to other metals that are known risk factors for cardiovascular diseases was assessed according to whether the workers had undergone medical check-ups for cadmium, chromium, nickel, or arsenic levels during the same period. A history of exposure to other metals was defined as occupational exposure to $\geq 1$ of the heavy metals mentioned above while employed by the same company. 


\section{Statistical analysis}

We used Cox's proportional hazards modelling to estimate adjusted hospital admission hazard ratios (AHR) for cardiovascular diseases. The AHR of cardiovascular diseases for each BLL grade $(10-20$ and $\geq 20 \mu \mathrm{g} / \mathrm{dL})$ were compared with that of the reference grade $(<10$ $\mu \mathrm{g} / \mathrm{dL})$. Age was divided into six groups $(<35,35-39$, $40-44,45-49,50-54$, and $\geq 55$ years) using global risk assessment scoring (10). We adjusted for age and record of exposure to other metals (yes or no). When estimating linear trends, the BLL grades $(<10,10-20$, and $\geq 20 \mu \mathrm{g} /$ dL) were considered continuous variables.

We used time-dependent covariate analysis to explore whether our proportional hazards assumptions were affected by age. The time-dependent covariate of age was not significant $(\mathrm{P}=0.22)$; thus, we removed the age-product term from the model. SPSS version 20.0 for Windows (SPSS, Inc, IBM, Armonk NY, USA) was used for the statistical analyses, and a P-value $<0.05$ was considered to indicate statistical significance.

\section{Results}

The overall characteristics of the study subjects are shown in table 1. We followed-up 53970 male workers during 2000-2005 over a total of 200766 person-years. The person-year follow-ups were 142926,37428 , and 20412 for those with BLL $<10,10-20$, and $\geq 20 \mu \mathrm{g} / \mathrm{dL}$, respectively. There were 40370 (74.8\%), $8886(16.5$ $\%)$ and $4714(8.7 \%)$ workers for those with BLL $<10$,
$10-20$, and $\geq 20 \mu \mathrm{g} / \mathrm{dL}$, respectively. Most subjects in all BLL categories were aged $<35$ years. The mean age of the subjects with a BLL $\geq 20 \mu \mathrm{g} / \mathrm{dL}$ [39.0, standard deviation (SD) 10.4 years] was higher than that of the other BLL groups $(\mathrm{P}<0.05)$. The geometric mean BLL was 6.46 (SD 2.22) $\mu \mathrm{g} / \mathrm{dL}$. No difference in terms of the duration of lead exposure was evident among the BLL groups. Subjects with a BLL $\geq 20 \mu \mathrm{g} / \mathrm{dL}$ were less likely to be exposed to other metals than were those with low BLL grades $(\mathrm{P}<0.05)$.

Over the 200766 person-years of follow-up, 2000 subjects were admitted to the hospital with "diseases of the circulatory system" (codes I00-I99). Of these subjects, $143(7.2 \%)$ were hospitalized with more than two sub-classifications of cardiovascular disease. The AHR [1.78, 95\% confidence interval $(95 \% \mathrm{CI}) 1.17-2.72]$ for ischemic heart disease (IHD) was significantly higher among workers with a BLL $\geq 20 \mu \mathrm{g} / \mathrm{dL}$ than those with a BLL $\leq 10 \mu \mathrm{g} / \mathrm{dL}$. The AHR (1.93, 95\% CI 1.13-3.29) for angina pectoris was significantly higher among workers with a BLL $\geq 20 \mu \mathrm{g} / \mathrm{dL}$ than those with a BLL $\leq 10 \mu \mathrm{g}$ / dL. The AHR (1.52, 95\% CI 1.00-2.31) for cerebrovascular disease was significantly higher among workers with a BLL of $10-20 \mu \mathrm{g} / \mathrm{dL}$ than those with a BLL $\leq 10$ $\mu \mathrm{g} / \mathrm{dL}$. The AHR among workers with a BLL of $10-20$ $\mu \mathrm{g} / \mathrm{dL}(2.04,95 \%$ CI $1.12-3.72)$ and a BLL $\geq 20 \mu \mathrm{g} / \mathrm{dL}$ (2.24, 95\% CI 1.14-4.39) for cerebral infarction were significantly higher than those with a BLL $\leq 10 \mu \mathrm{g} / \mathrm{dL}$. IHD, cerebrovascular disease, angina pectoris (marginally significant), and cerebral infarction all showed a positive linear relationship with BLL. In terms of other circulatory system diseases, no significant differences or trends were evident according to BLL (table 2).

Table 1. General characteristics of lead-exposed workers according to blood lead levels. [SD=standard deviation.]

\begin{tabular}{|c|c|c|c|c|c|c|c|c|c|c|c|c|}
\hline & \multicolumn{12}{|c|}{ Blood lead level } \\
\hline & \multicolumn{4}{|c|}{$<10 \mu \mathrm{g} / \mathrm{dL}$ (142 926 person-years) } & \multicolumn{4}{|c|}{ 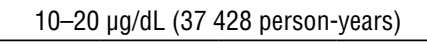 } & \multicolumn{4}{|c|}{$\geq 20 \mu \mathrm{g} / \mathrm{dL}$ (20 412 person-years) } \\
\hline & $\mathrm{N}$ & $\%$ & Mean & SD & $\mathrm{N}$ & $\%$ & Mean & SD & $\mathrm{N}$ & $\%$ & Mean & SD \\
\hline Age (years) & & & 36.6 & 9.7 & & & 37.7 & 9.9 & & & $39.0^{\mathrm{a}}$ & 10.4 \\
\hline$<35$ & 20554 & 50.9 & & & 4011 & 45.1 & & & 1924 & 40.8 & & \\
\hline $35-39$ & 6068 & 15.0 & & & 1470 & 16.5 & & & 763 & 16.2 & & \\
\hline $40-44$ & 4951 & 12.3 & & & 1300 & 14.6 & & & 681 & 14.4 & & \\
\hline $40-49$ & 4370 & 10.8 & & & 975 & 11.0 & & & 570 & 12.1 & & \\
\hline $50-54$ & 2692 & 6.7 & & & 570 & 6.4 & & & 373 & 7.9 & & \\
\hline$\geq 55$ & 1735 & 4.3 & & & 560 & 6.3 & & & 403 & 8.5 & & \\
\hline $\begin{array}{l}\text { Lead exposure } \\
\text { duration (years) }\end{array}$ & & & 10.3 & 7.4 & & & 10.0 & 6.6 & & & 9.6 & 6.4 \\
\hline$<10$ & 24305 & 60.2 & & & 5485 & 61.7 & & & 3006 & 63.8 & & \\
\hline $10-19$ & 10433 & 25.8 & & & 2583 & 29.1 & & & 304 & 27.7 & & \\
\hline$\geq 20$ & 5632 & 14.0 & & & 818 & 9.2 & & & 404 & 8.6 & & \\
\hline $\begin{array}{l}\text { Exposure to } \\
\text { other metals }\end{array}$ & & & & & & & & & & & & \\
\hline Yes & 10208 & 25.3 & & & 1641 & 18.5 & & & 625 & 13.3 & & \\
\hline No & 30162 & 74.7 & & & 7245 & 81.5 & & & 4089 & $86.7^{b}$ & & \\
\hline Total & 40370 & 100.0 & & & 8886 & 100.0 & & & 4714 & 100.0 & & \\
\hline
\end{tabular}

a $P<0.05$ by ANOVA.

b $P<0.05$ by chi-square test. 
Table 2. Adjusted admission hazards ratio of cardiovascular diseases according to blood lead levels. [AHR=adjusted hospital admission hazard ratio; $95 \% \mathrm{Cl}=95 \%$ confidence interval]

\begin{tabular}{|c|c|c|c|c|c|c|c|c|}
\hline \multirow[t]{3}{*}{ Disease code } & \multicolumn{7}{|c|}{ Blood lead level } & \multirow{3}{*}{$\begin{array}{l}\text { P for } \\
\text { trend }\end{array}$} \\
\hline & \multirow{2}{*}{$\begin{array}{c}<10 \mu \mathrm{g} / \mathrm{dL}^{\mathrm{a}} \\
(142926 \\
\text { person-years } \\
\text { Workers }(\mathrm{N})\end{array}$} & \multicolumn{3}{|c|}{$\begin{array}{c}10-20 \mu \mathrm{g} / \mathrm{dL} \\
\text { (37 } 428 \text { person-years) }\end{array}$} & \multicolumn{3}{|c|}{$\begin{array}{c}\geq 20 \mu \mathrm{g} / \mathrm{dL} \\
(20412 \text { person-years })\end{array}$} & \\
\hline & & Workers (N) & $\mathrm{AHR}^{\mathrm{b}}$ & $95 \% \mathrm{Cl}$ & Workers (N) & $\mathrm{AHR}$ & $95 \% \mathrm{Cl}$ & \\
\hline Diseases of the circulatory system (I00-199) & 1405 & 365 & 0.94 & $0.84-1.06$ & 230 & 1.04 & $0.90-1.19$ & 0.98 \\
\hline $\begin{array}{l}\text { Acute rheumatic fever (100-102) \& chronic } \\
\text { rheumatic heart diseases (105-109) c }\end{array}$ & 5 & 0 & & & 1 & & & \\
\hline Hypertensive diseases (I10-|15) & 150 & 55 & 1.20 & $0.88-1.64$ & 33 & 1.12 & $0.76-1.64$ & 0.36 \\
\hline Ischemic heart diseases (I20-I25) & 89 & 20 & 0.75 & $0.46-1.21$ & 30 & 1.78 & $1.17-2.72$ & 0.05 \\
\hline Angina pectoris (I20) & 49 & 11 & 0.69 & $0.34-1.34$ & 20 & 1.93 & $1.13-3.29$ & 0.07 \\
\hline Acute myocardial infarction $(121,122,124)$ & 20 & 6 & 0.95 & $0.38-2.37$ & 6 & 1.45 & $0.57-3.68$ & 0.53 \\
\hline $\begin{array}{l}\text { Pulmonary heart disease \& diseases of pulmonary } \\
\text { circulation (126-128) }\end{array}$ & 1 & 0 & & & 1 & & & \\
\hline Other forms of heart disease (I30-|52) & 81 & 24 & 0.88 & $0.55-1.39$ & 19 & 1.06 & $0.63-1.76$ & 0.99 \\
\hline Cerebrovascular diseases (I60-I69) & 70 & 33 & 1.52 & $1.00-2.31$ & 21 & 1.53 & $0.93-2.51$ & 0.04 \\
\hline Cerebral hemorrhage (160-I62) & 22 & 8 & 1.22 & $0.54-2.76$ & 4 & 1.03 & $0.35-3.03$ & 0.81 \\
\hline Cerebral infarction (I63-I64) & 27 & 18 & 2.04 & $1.12-3.72$ & 13 & 2.24 & $1.14-4.39$ & 0.01 \\
\hline Diseases of arteries, arterioles \& capillaries (I70-I79) & 10 & 6 & 2.09 & $0.75-5.80$ & 3 & 1.72 & $0.46-6.40$ & 0.24 \\
\hline $\begin{array}{l}\text { Diseases of veins, lymphatic vessels \& lymph nodes, } \\
\text { NEC (I80-I89) }\end{array}$ & 1088 & 261 & 0.90 & $0.78-1.03$ & 149 & 0.93 & $0.78-1.11$ & 0.17 \\
\hline $\begin{array}{l}\text { Other \& unspecified disorders of the circulatory } \\
\text { system (195-199) }\end{array}$ & 5 & 0 & & & 2 & & & \\
\hline
\end{tabular}

a Reference.

${ }^{b}$ Adjusted for age and exposure to other metals.

c Categories with $<10$ cases were excluded from the Cox-regression model.

\section{Discussion}

IHD and stroke (infarction and hemorrhage) share many of the same risk factors, such as age, smoking, and hypertension. Age is one of the most powerful risk factors for both IHD and stroke (11). However, IHD and cerebral infarction are closely associated with atherosclerosis, whereas alcohol consumption is closely associated with an elevated risk of cerebral hemorrhage (12). In terms of the theoretical pathogenesis of lead toxicity (4), BLL might be more closely related to IHD and cerebral infarction than to cerebral hemorrhage. As expected, we found a significant association between BLL and risk of major cardiovascular diseases. Notably, the strong association between cerebral infarction and BLL strengthened our hypothesis. Of note, the AHR for cerebrovascular disease and cerebral infarction were significantly higher among workers with a BLL of $10-20 \mu \mathrm{g} / \mathrm{dL}$ than those with a $\mathrm{BLL} \leq 10 \mu \mathrm{g} / \mathrm{dL}$; this finding has major implications for the establishment of a standard BLL. The AHR is higher at BLL lower than the currently permissible level $(30 \mu \mathrm{g} /$ $\mathrm{dL}$ ) suggested by the Occupational Safety and Health Administration (OSHA) (13). However, acute myocardial infarction was not associated with BLL; this was likely due to the widened CI associated with the small number of cases resulting from IHD subdivision. Additionally, unstable angina (I20.0) with acute myocardial infarction should belong to the acute coronary syndrome. However, we were unable to access the unstable angina code, which is a subcategory of angina pectoris (I20). We do not have a clear explanation for the lack of association between cerebral hemorrhage and BLL. Although atherosclerosis disfavors the risk of cerebral hemorrhage (12, 14), hypertension is significant factor related to cerebral hemorrhage (12).

McElvenny et al (15) previously found that the standardized mortality ratios for IHD and cerebrovascular disease were significantly associated in workers with a high BLL. Lustberg \& Silbergeld (16) found a significant relationship between a BLL $>20 \mu \mathrm{g} / \mathrm{dL}$ and mortality from circulatory system diseases, and Menke et al (17) reported that a BLL $>2 \mu \mathrm{g} / \mathrm{dL}$ was significantly associated with mortality from myocardial infarction or stroke in the general population.

Studies on the circulatory effects of lead have focused primarily on hypertension. Although a recent large-scale cross-sectional study using NHANES IV data found that hypertension was not associated with BLL (18), previous studies have implied that lead exposure contributes to the development of hypertensive disease. However, hypertensive disease was no more prevalent among workers with a high BLL than those with a low BLL in our cohort. This may reflect our use of hospital admission rather than outpatient data. Almost all patients with acute IHD and cerebrovascular diseases are admitted to the hospital; most community-dwelling individuals with hypertensive disease are not admitted, but instead receive outpatient care. We thus underestimated the incidence of hypertensive disease. Moreover, when patients are hospitalized for multiple diagnoses, 
the NHICD does not reveal the principal diagnosis. Patients with hypertension were likely hospitalized for treatment of some other problematic disease. In our cohort, $32 \%$ of the cases with hypertensive disease had previously been hospitalized to treat IHD or cerebrovascular disease (data not shown). Had we checked other diagnostic codes, such as those for gastrointestinal diseases, the proportion of patients with multiple diagnoses would have increased. Thus, significant among-group differences in terms of the "hypertensive diseases" category (I10-I15) may be lacking.

The principal hazard exposure-related diseases termed "diseases of arteries, arterioles and capillaries" (codes I70-I79) are atherosclerosis and peripheral arterial disease (PAD). Earlier epidemiological studies found that environmental exposure to lead was associated with PAD development $(19,20)$. PAD increases the risk of mortality from cardiovascular disease (21). However, only a few patients were admitted with PAD. The "diseases of veins, lymphatic vessels and lymph nodes, NEC" (I80-I89) are temporary complications that develop in the hospital during the treatment of other diseases. In particular, varicose veins are associated with mechanical conditions such as work involving standing, regardless of environmental hazards.

\section{Strengths and limitations}

The first strength of our prospective cohort study is that the independent variable was not an intermediate stage of disease (eg, high blood pressure) but rather admission to the hospital, which affords good diagnostic accuracy. The accuracy and reliability of hospitalization diagnoses will be better than those of outpatient clinics. A few studies have examined the inpatient diagnostic validity of cardiovascular disease using the NHICD database in Korea, which they determined to be good. The accuracy with which acute myocardial infarction was diagnosed by applying the ICD-10 to the Korean NHICD database was $>70 \%$ (22), and the criteria for ischemic stroke had a sensitivity and specificity of approximately $>90 \%$ (23). However, in terms of hypertensive disease, although diagnostic accuracy was ensured, we likely underestimated the case numbers. Thus, serious diseases are evaluated well compared with mild diseases using hospitalization data. The second strength is that we recorded the outcomes of almost 54000 workers. Our cohort included most lead-exposed workers defined by the "Industrial Safety and Health Act of the Republic of Korea" and was thus very representative.

Our results should be interpreted cautiously. First, we were unable to consider other major modifiable risk factors such as smoking, body mass index, psychosocial stressors, socioeconomic status, and antihypertensive medication because individual data were lacking. We mentioned this limitation in our previous work (24, $25)$, which can be summarized as follows. Although the smoking rate, which was recorded for only $10 \%$ of the cohort, did not differ significantly in the $\geq 10 \mu \mathrm{g} /$ $\mathrm{dL}$ and $<10 \mu \mathrm{g} / \mathrm{dL}$ groups, our ability to estimate and interpret the overall results is limited. The data on body mass index and cholesterol did not differ substantially from those on smoking. We also had no access to socioeconomic data; however, as most of our subjects were manual workers, they may have been similar to one another with regard to race, socioeconomic status, and education. Second, statistical adjusting does not completely control for confounding. Indeed, residual confounding occurs depending on how variables are transformed (26). It is possible that the positive relationship between the BLL and increased AHR of cardiovascular diseases is related to the association between cardiovascular disease and age. Lastly, a "healthy worker" effect may have been in play in that workers unfit to work would have been excluded. Those with cardiovascular diseases are less likely to be employed and hence would be excluded from the workplace.

In conclusion, we found both an association and a probable causal relationship between BLL and increased hospital admission to treat IHD and cerebrovascular diseases. Further studies are certainly needed to elucidate the potential role of BLL in the development of cardiovascular diseases, but our study indicates that greater efforts must be made to reduce lead exposure. We suggest that the American Conference of Governmental Industrial Hygienists and OSHA have set an overly high BLL standard $(30 \mu \mathrm{g} / \mathrm{dL})$. This should be lowered to prevent the cardiovascular effects of lead exposure.

\section{Acknowledgements}

We thank the Korea Occupational Safety and Health Agency and National Health Insurance Service. The authors declare no conflicts of interest.

\section{References}

1. Peters JL, Kubzansky LD, Ikeda A, Fang SC, Sparrow D Weisskopf MG, et al. Lead concentrations in relation to multiple biomarkers of cardiovascular disease: the Normative Aging Study. Environ Health Perspect. 2012;120:361-6. https://doi.org/10.1289/ehp.1103467.

2. Skerfving S, Bergdahl IA. Lead. In: Nordberg GF, Fowler BA, Nordberg M, editors. Handbook on the Toxicology of Metals, 4th edn. London: Elsevier B.V.; 2014. p. 911-67.

3. Fischbein $\mathrm{A}, \mathrm{Hu} \mathrm{H}$. Occupational and environmental exposure 
to lead. In: Rom WN, Markowitz SB, editors. Environmental and Occupational Medicine, 4th edn. Philadelphia: Wolters Kluwer/Lippincott Williams \& Wilkins; 2007. p. 954-90.

4. Navas-Acien A, Selvin E, Sharrett AR, Calderon-Aranda E, Silbergeld E, Guallar E. Lead, cadmium, smoking, and increased risk of peripheral arterial disease. Circulation. 2004;109:3196-201. https://doi.org/10.1161/01. CIR.0000130848.18636.B2.

5. Schober SE, Mirel LB, Graubard BI, Brody DJ, Flegal KM. Blood lead levels and death from all causes, cardiovascular disease, and cancer: results from the NHANES III Mortality Study. Environ Health Perspect. 2006;114:1538-41. https:// doi.org/10.1289\%2Fehp. 9123

6. Poręba R, Gać P, Poręba M, Andrzejak R. Assessment of cardiovascular risk in workers occupationally exposed to lead without clinical presentation of cardiac involvement. Environ Toxicol Pharmacol. 2012;34:351-7. https://doi.org/10.1016/j. etap.2012.05.008.

7. Navas-Acien A, Guallar E, Silbergeld EK, Rothenberg SJ. Lead exposure and cardiovascular disease-a systematic review. Environ Health Perspect. 2007;115:472-82. https://doi. org/10.1289/ehp.9785.

8. Kim KR, Lee SW, Paik NW. Cross-sectional analysis of blood lead level of entire Korean lead workers. Ind Health. 2006;44:318-27. https://doi.org/10.2486/indhealth.44.318.

9. Schwartz BS, Hu H. Adult lead exposure: time for change. Environ Health Perspect. 2007;115:451-4. https://doi. org/10.1289/ehp.9782.

10. Grundy SM, Pasternak R, Greenland P, Smith S Jr, Fuster V. Assessment of cardiovascular risk by use of multiplerisk-factor assessment equations: a statement for healthcare professionals from the American Heart Association and the American College of Cardiology. Circulation. 1999;100:148192. https://doi.org/10.1161/01.CIR.100.13.1481.

11. Soler EP, Ruiz VC. Epidemiology and Risk Factors of Cerebral Ischemia and Ischemic Heart Diseases: Similarities and Differences. Curr Cardiol Rev. 2010;6:138-49. https://doi.or g/10.2174/157340310791658785.

12. Andersen KK, Olsen TS, Dehlendorff C, Kammersgaard LP. Hemorrhagic and ischemic strokes compared: stroke severity, mortality, and risk factors. Stroke. 2009;40:2068-72. https:// doi.org/10.1161/STROKEAHA.108.540112.

13. Occupational Safety and Health Administration (OSHA). Occupational Safety and Health Standards: Toxic and Hazardous Substances: Lead. CFR 1910.1025. 2015.

14. Lee TH, Tseng MC, Chen CJ, Lin JL. Association of high body lead store with severe intracranial carotid atherosclerosis. Neurotoxicology. 2009;30:876-80. https://doi.org/10.1016/j. neuro.2009.07.004.

15. McElvenny DM, Miller BG, MacCalman LA, Sleeuwenhoek A, van Tongeren M, Shepherd K, et al. Mortality of a cohort of workers in Great Britain with blood lead measurements. Occup Environ Med. 2015;72:625-32. https://doi.org/10.1136/ oemed-2014-102637.
16. Lustberg M, Silbergeld E. Blood lead levels and mortality. Arch Intern Med. 2002;162 :2443-9. https://doi.org/10.1001/ archinte.162.21.2443.

17. Menke A, Muntner P, Batuman V, Silbergeld EK, Guallar E. Blood lead below $0.48 \mathrm{micromol} / \mathrm{L}(10 \mathrm{microg} / \mathrm{dL})$ and mortality among US adults. Circulation. 2006;114:1388-94. https://doi.org/10.1161/CIRCULATIONAHA.106.628321.

18. Hara A, Thijs L, Asayama K, Gu YM, Jacobs L, Zhang ZY, et al. Blood pressure in relation to environmental lead exposure in the national health and nutrition examination survey 2003 to 2010. Hypertension. 2015;65:62-9. https://doi.org/10.1161/ HYPERTENSIONAHA.114.04023.

19. Nash D, Magder L, Lustberg M, Sherwin RW, Rubin RJ, Kaufmann RB, et al. Blood lead, blood pressure, and hypertension in perimenopausal and postmenopausal women. JAMA. 2003;289:1523-32. https://doi.org/10.1001/ jama.289.12.1523.

20. Muntner P, Menke A, DeSalvo KB, Rabito FA, Batuman V. Continued decline in blood lead levels among adults in the United States: the National Health and Nutrition Examination Surveys. Arch Intern Med. 2005;165:2155-61. https://doi. org/10.1001/archinte.165.18.2155.

21. Chang NT, Chan CL, Lu YT, Hsu JC, Hsu YN, Chu D, et al. Invasively-treated incidence of lower extremity peripheral arterial disease and associated factors in Taiwan: 2000-2011 nationwide hospitalized data analysis. BMC Public Health. 2013;13:1107. https://doi.org/10.1186/1471-2458-13-1107.

22. Kimm HJ, Yun JE, Lee SH, Jang Y, Jee SH. Validity of the diagnosis of acute myocardial infarction in Korean national medical health insurance claims data. Korean Circ J. 2012;42:10-5. https://doi.org/10.4070/kcj.2012.42.1.10.

23. Park TH, Choi JC. Validation of Stroke and Thrombolytic Therapy in Korean National Health Insurance Claim Data. J Clin Neurol. 2016;12:42-8. https://doi.org/10.3988/ jen.2016.12.1.42.

24. Yoon JH, Ahn YS. The association between blood lead level and clinical mental disorders in fifty thousand lead-exposed male workers. J Affect Disord. 2016;190:41-6. https://doi. org/10.1016/j.jad.2015.09.030.

25. Kim MG, Ryoo JH, Chang SJ, Kim CB, Park JK, Koh SB, Ahn YS. Blood Lead Levels and Cause-Specific Mortality of Inorganic Lead-Exposed Workers in South Korea. PLoS One. 2015;10:e0140360. https://doi.org/10.1371/journal. pone. 0140360 .

26. Sainani K. The limitations of statistical adjustment. PM R. 2011.3:868-72. http://doi.org/10.1016/j.pmrj.2011.06.006

Received for publication: 4 January 2017 